\title{
Libanon og krigen i juli 2006 i lys av statsbyggingsteori
}

SHAB'A-GÅRDENE ${ }^{1}$ I HISTORISK PERSPEKTIV

Hva er bakgrunnen for den libanesiske regjeringens krav på suverenitet over Shab'a-gårdene, et grenseområde som myndighetene i nærmere åtti år ikke har vist nevneverdig interesse for å innlemme i landet? Hvorfor fremmes kravet nå?

Av Rania Maktabi, statsviter ved Høgskolen i Østfold.

I sommer fulgte verden en månedslang krig mellom Hizballahs paramilitære styrker og Israel, i kjølvannet av at Hizballah I2. juli drepte åtte og kidnappet to israelske soldater. Konflikten har nå kjølnet noe, etter at FNS sikkerhetsråd II. august 2006 enstemmig vedtok Resolusjon I70I (heretter kalt SR I7OI). Generalsekretæren anmodes i denne resolusjonen om å finne "proposals to delineate the international borders of Lebanon, especially in those areas where the border is disputed or uncertain, including by dealing with the Shebaa Farms and report to the Council within thirty days". ${ }^{3}$

Hizballahs aksjon skjedde i hjertet av dette 25 kvadratkilometer store trekantlignende grenseområdet mellom Israel, Libanon og Syria. I dag er området okkupert av Israel, men det er fortsatt uklart hvilken stat som kan påberope seg suverenitet over det etter internasjonal rett. ${ }^{4}$ Før 1967, da Israel okkuperte Golanhøydene og innlemmet Shab'a-gårdene som en del av okkuperte territorier, besto området av frodige marker der tobakk, frukt og grønnsaker ble dyrket takket være vanntil- førsler fra Hermelfjellet. Nå tjener det konfliktfylte og følgelig ubebodde området utelukkende militære formål.

Strategisk beliggenhet og vannressurser utgjør opplagte kilder til interessekonflikt. Stormaktene som dominerte området under mandattiden, bidro med tilfeldige grensedragninger, som også ble uklart nedtegnet på kart. Syriske og libanesiske myndigheter fulgte opp med laber og tvetydig interesse med hensyn til å regulere formell administrativ praksis. Sammen danner dette det historiske bakteppet for Shab'a-gårdenes uklare suverenitet. Dertil utgjør Israels opprettelse som stat i I948, og kartendringer som følge av demilitariserte soner rundt Israel, også kontinuerlige kilder til konflikt.

I mai 2000, to måneder etter at Israel hadde trukket seg ut av Sør-Libanon, påpekte den libanesiske professoren $\mathrm{i}$ internasjonal rett Chibli Mallat følgende: "Old-style sovereignty and power symbols firmly continue as the name of the game: for peace to obtain, boundaries need to be defined down to the last centimeter of land". ${ }^{5}$ Kimen til konflikten mellom Israel 
og Libanon er å finne i tvister om Shab'agårdenes grenser og suverenitet. Den libanesiske regjeringen insisterer på at Israel ikke har trukket seg helt ut av libanesisk territorium, og henviser til grenser staket ut i I920 da Libanon ble etablert som stat. Hizballah har inntatt en posisjon der kampen om grensetrakter defineres som motstandskamp mot okkupantstaten Israel. Israel anklager på sin side Hizballah for å bruke disputten over Shab'a-gårdene som et påskudd for å legitimere angrep mot landet. Kontroversen over området er imidlertid ikke "oppfunnet" av Hizballah, framhever den israelske historikeren Asher Kaufmann ved Hebrew University i Jerusalem, selv om partiet utnytter den for å nå egne politiske mål. ${ }^{6}$

Libanesiske myndigheter har i nærmere åtti år - fra 1923 og fram til 2000 - vist liten interesse for, eller vilje til, å regulere Shab'a-gårdene som en del av landet. Så hva er bakgrunnen for den libanesiske regjeringens nåværende krav på suverenitet over dette grenseområdet? Hva ligger til grunn for denne nye iveren etter grensedragning, og hvorfor fremmes kravet om dette nå?

\section{Krigen i 2006}

Som følge av fokus på eksterne makters interesser (særlig Iran og Syria) har Libanon vært portrettert som en "slagmark for andres krig”. I mediedekningen av krigen framstilles libanesere som tilskuere til "historien [som] ruller over landet deres".

Denne skildringen impliserer at libaneserne brukes som politiske brikker i andre aktørers spill, og at landet er et uforskyldt bytte for andre staters interesser. Dette synet er etter min mening unyansert. Videre er det utilstrekkelig som utgangs- punkt for å forstå Libanons interne, politiske forhold. Disse er preget av målsettinger og interesser som skifter i takt med endringer av nasjonale, regionale og internasjonale maktforhold.

Med "interne" politiske forhold, tenker jeg her ikke bare på nasjonale aktører (politikere og ledere av de ulike konfesjonene, media og organisasjoner), men på strukturelle aspekter ved Libanon som stat: Hva slags statskonstruksjon danner den geografiske rammen rundt dette lille pluralistiske samfunnet?

Når jeg her retter oppmerksomheten mot enkelte strukturelle omstendigheter, reduseres ikke betydningen av regionale og internasjonale forhold. Jeg forsøker snarere å klargjøre bakgrunnen for de eksterne aktørers innflytelse på libanesisk politikk. Slik setter jeg krigen som startet i det konfliktfylte området der Shab'a-gårdene ligger i historisk lys, med særlig fokus på hva statsvitere kaller statsbygging.

\section{Statsbygging}

Kort sagt kan man si at "statsbygging" er det ingeniørmessige og arkitektoniske utgangspunktet for dannelsen av en territoriell og politisk avgrenset enhet som vi kjennetegner som "stat". Denne avgrensningen skjer ved at et territorium skilles ut fra andre enheter og anerkjennes av fellesskapet av stater. I våre dager skjer dette ved en stats opptak som medlem av De forente nasjoner (FN).

I tillegg til en utadrettet markering, innebærer statsbygging en sentraliseringsprosess innad der politiske myndigheter $i$ byene øker sin politiske autoritet på bekostning av periferien (agrare områder, fjellstrøk og grensetrakter). For å oppnå dette er to funksjoner essensielle: skattelegging 
og verneplikt. ${ }^{8}$ Innkreving av skatt skjer dels for å betale kostnadene av en statsadministrasjon som koordinerer sentralisering av makt (byråkrati, politikere, kongen eller presidenten), og dels for å lønne den politiske autoritets evne til å forlange og opprettholde intern orden (politi og rettsvesen) og ekstern sikkerhet (hær). I begge disse funksjonene foregår utstrakt

\section{mom \\ Hizballah har inntatt en posisjon der kampen om grensetrakter defineres som motstandskamp mot okkupantstaten Israel.}

bruk av makt (fra myndigheters side) for å kreve inn penger til statskassa, og for å tvinge familier til å ofre unge menns liv for landet. Samtidig utøver innbyggerne ulike former for motmakt, som for eksempel uvilje mot å betale skatt, la familiens menn verve seg til hæren eller underordne seg ulike beslutninger som forandrer livsvilkårene deres. Eksempler her kan være språklige krav om å tilegne seg et utvalgt nasjonalt språk, tvungen konvertering til en spesifikk religion, eller krav om urbanisering og forflyttning. Sluttresultatet av maktsentraliseringen er - teoretisk sett - et politisk lederskap med økt mulighet og evne til å initiere lovendringer og løse ulike type konflikter som alltid følger med enhver form for maktbruk. ${ }^{9}$

\section{Spillet om Shab'a og andre grenseområder ${ }^{10}$} I suverenitetsdisputten om Shab'a-gårdene og andre grensetrakter i Libanon møtes fortid og nåtid på en måte som skyver statsteoretiske prinsipper i forgrunnen. Hvor- dan ble staten formet? Hvilke grenser ble tegnet, av hvem og når? Hvem bor/bodde i dette området, og hvilken nasjonalitet har/hadde de? Disse spørsmålene kan forfølges ved å rette oppmerksomheten mot to dimensjoner ved statsbygging: geopolitiske og statsborgerlige dimensjoner.

"Geopolitiske dimensjoner" omfatter spørsmål knyttet til territoriell kartlegging og demarkasjon av grenser mellom grensestater. Grensetvister handler om involverte staters strategiske interesser, og kjennetegnes ofte av militær konfrontasjon der regionale stormaktsinteresser er en viktig del av bildet. Dette er et politikkområde i skjæringspunktet mellom nasjonal, regional og internasjonal politikk, der internasjonal rett og FN spiller en sentral rolle ved å legitimere våpenhvilegrenser.

Den libanesiske statens offisielle krav på Shab'a-gårdene er av nyere dato og ble presentert for FN første gang den 4 . mai 2000 i kjølvannet av Israels tilbaketrekning fra Sør-Libanon. ${ }^{\text {II }}$ Libanesiske myndigheter giorde FN oppmerksom på at Israel ikke hadde trukket seg helt ut av Libanon som (blant annet) også omfatter Shab'a-gårdene. I en senere rapport fra Sikkerhetsrådet datert I8. juni 2000, noteres det at "[t]he Lebanese Government advised that the line used for the purpose of confirming the withdrawal did not conform in three locations to the internationally recognized border with Israel. Concerning the Shab'a farmlands, both Lebanon and Syria state that this land belongs to Lebanon..12

Disputten om Shab'a-gårdene kan føres tilbake i tid til da landsbyen Shab'a (som fortsatt ligger på den libanesiske siden av grensen mot Syria) hadde I4 tilhørende gårder. I I923 inngikk imidlertid Frankrike og Storbritannia, datidens mandatmakter, 




Kart over Shab’a-gårdene. Lastet ned fra Wikipedia. http://en.wikipedia.org/wiki/Shebaa_Farms, lesedato 3. september 2006.

Paulet-Newcombe avtalen. Denne avtalen omrokerte grensene mellom Palestina, Libanon og Syria, slik at grenselinjen for Libanon ble trukket lenger nord- og vestover. ${ }^{13}$ Som resultat av denne endringen ble Shab'a-gårdene skilt ut fra landsbyen Shab'a, og plassert innenfor Syrias grenser (Syria var også under fransk mandatstyre fra I920 til I946). Gårdeierne bodde i landsbyen Shab'a, som i følge Paulet-Newcombe grensedragningen fortsatt lå på libanesisk side. Syriske myndigheter har fra I923 og fram til I967, da Israel okkuperte området - administrert gårdene som libanesiske. Dette har de gjort ved å godta at gårdeierne betalte skatt til libanesiske myndigheter i byene Hasbayya og Marji'yun, framfor syriske myndigheter i Quneitra, påpeker Kaufman. Han understreker videre at definering av grenser innebærer tre skritt: I) allokering av et område til en stat; II) avgrensning av dette området ved å nedtegne grensen på et skriftlig dokument; III) demarkasjon av området på bakken. Ifølge ham har kun allokeringsprosessen funnet sted når det gjelder Shab'a-gårdene: Libanon og Syria har siden landenes uavhengighet på I940tallet vært enige om å administrere området som libanesisk territorium. En felles regjeringsoppnevnt kommisjon erkjente i I964 at Shab'a er libanesisk, men dette ble ikke formalisert. ${ }^{\mathrm{I}}$ I redegjørelser mellom Syria og Libanon har syrerne erkjent at Shab'a er libanesisk. Denne erkjennelsen gjorde syrerne overfor FN i 2000, da Israel trakk seg ut, og nå nylig, i kjølvannet av krigen i 2006.

Det finnes med andre ord en gjensidig forståelse mellom Syria og Libanon om at 
Shab'a tilhører Libanon. Det mangler imidlertid en offisiell avgrensning og en internasjonalt godkjent demarkasjon.

Mangelen på en offisiell anerkjennelse av Shab'a-gårdene som libanesisk territorium, henger sammen med flere faktorer, deriblant Syrias erklærte holdning om at Libanon og Syria er "spesielle naboer". Dette avspeiles ved fraværet av en syrisk ambassade i Libanon, og ved at Libanons grense mot øst fortsatt ikke er offisielt demarkert.

Hvilke interesser libanesiske myndigheter har hatt av å la vore å demarkere grenser og utøve suverenitet er mer komplisert og sammensatt. Én faktor er statens manglende militære evne til å utøve sin politiske myndighet i de sørlige traktene av landet. Økonomisk sett har myndighetene utøvd en utstrakt grad av laissez-faire-politikk der skatter og avgifter er blitt holdt på et absolutt minimum. Dette har resultert i en slunken statskasse og knappe ressurser til å bygge opp en slagkraftig hær som kan sørge for befolkningens sikkerhet og til å bygge opp et minimum av offentlige tjenester (infrastruktur, helse- og skolesystem). Allerede mot slutten av i950-tallet vokste det fram en effektiv væpnet bevegelse under ledelse av Den palestinske frigjøringsorganisasjonen (PLO) som utførte geriljavirksomhet over grensen mot Israel. ${ }^{\text {I5 }}$ I kjølvannet av I967-krigen, da Israel okkuperte Vestbredden og Golanhøydene, sto sentralmyndighetene i Libanon totalt maktesløse $\mathrm{i}$ forhold til å stagge de væpnede kampene mellom palestinerne og israelerne i Sør-Libanon. ${ }^{\mathrm{i}}$ Det er denne forklaringen som oftest blir trukket fram som begrunnelse for sentralmyndighetenes fravær i sør.

Andre faktorer som muligens kan belyse den diplomatiske tafattheten overfor syriske myndigheter, kan knyttes til det jeg vil kalle "statsborgerlige dimensjoner" ved statsbygging. Disse omfatter en politisk definisjon og dokumentasjon av innbyggeres nasjonalitet innen et territorium. Innbyggerne anerkjennes dermed som statens borgere ved ulike former for sertifisering: utstedelse av identitetskort, reisedokumenter, pass, registrering $i$ en folketelling eller i manntallet. Dette politikkområde er helt og holdent under statlig myndighet, og antyder en stats makt til å definere hvem som utgjør dens legitime borgere.

I intern libanesisk politikk har de statsborgerlige dimensjonene ved statsbygging vært et stridsspørsmål siden I930- og 40tallet. Langs Libanons grenseområde mot Syria og Israel eksisterte det nemlig - fram til I994 - betydelige grupper av statsløse innbyggere. De statsløse hevdet at de var libanesere, men de ble ikke offisielt anerkjent eller "sertifisert" som borgere. Etter Libanons uavhengighet i I943 forble de statsløse innbyggere av libanesisk herkomst. De fleste av disse var innbyggere og etterkommere av innbyggere ved grensetraktene. Anslagene over hvor mange som tilhørte denne gruppen statsløse varierer. Opplysninger jeg samlet inn i 1994 viser imidlertid at rundt 80.000-90.000 personer enten ikke har vært registret som innbyggere, eller de har hatt libanesiske identitetskort der det i feltet "nasjonalitet" sto "under utredning" (qayd ad-dars) eller "uspesifisert" (jinsiyya gair mu'ayyana). ${ }^{17}$ På midten av I980-tallet oppsto en merkbar interesse blant jurister og menneskerettsaktivister i landet for å bringe de statsløses juridiske status fram i lyset. Denne interessen ble også målbåret 
av Hizballah, som ble etablert i 1983 - i kjølvannet av Israels invasjon av Libanon i I982. Dermed ble dette trukket fram som et politisk problemområde som måtte løses. Brorparten av de berørte fikk libanesisk statsborgerskap i 1994 gjennom det som ble betegnet som et oppsiktsvekkende dekret. For første gang siden I968 innvilget staten søknader om libanesisk statsborgerskap til personer hvis individuelle klagesaker hadde vært fremmet siden I940-tallet. ${ }^{18}$

Libanesiske myndigheters mer eller mindre tilsiktete nedprioritering av å definere grensebeboernes nasjonale identitet kan muligens kaste lys over offisiell passivitet med henhold til å markere og definere landets territoriale grenser. En offisielt avtegnet grense mot Syria ville nemlig medføre at staten også måtte erkjenne at beboerne i disse grensestrøkene var å anse som libanesiske borgere. Ved å

Den libanesiske statens offisielle krav på Shab'a-gårdene ble presentert FN for første gang den 4. mai 2000.

unnlate å formalisere grensen mellom Libanon og Syria, "fritok" myndighetene seg selv ansvaret for å dokumentere disse individenes nasjonale identitet.

De som dyrket Shab'a-gårdene, er bosatt i landsbyen Shab'a og har libanesisk statsborgerskap, mest sannsynlig fordi de var landeiere. De tidligere gårdbrukerne innehar fortsatt dokumenter som viser eierskap til gårdene sine. ${ }^{19}$ For tusenvis av andre ubemidlete beboere av grensetraktene mellom Libanon og Syria var situasjo- nen en annen. Deres søknader om å få tilkjent statsborgerlige rettigheter ble sett på som problematisk av sentralmyndighetene, av politiske årsaker som blir nærmere belyst i neste avsnitt. Her er det tilstrekkelig å antyde at libanesiske myndigheters unnfallenhet i forhold til å markere grensetrakter offisielt, kan ha hatt interne politiske motiver.

\section{Territoriale utvidelser i Libanon anno 1920} Historisk sett ble både landsbyen Shab'a og dens tilhørende gårder administrert som en del av Syria under det osmanske riket (I517-I919). I I920 ble republikken Libanon etablert under fransk mandatstyre (I920-I943), og det som tidligere var kjent som den osmanske Sanjak of Mount Lebanon ble sterkt utvidet. Den osmanske sanjak utgjorde mindre enn halvparten av territoriet som etter utvidelsene i I920 dannet dagens Libanon. Den nye staten fikk en periode kallenavnet Greater Lebanon for å markere den territoriale utvidelsen.

Den nye staten anno I920 ble tatt i mot på ulik vis av Libanons "gamle" innbyggere i den osmanske sanjak og av de nye innbyggerne av Greater Lebanon. Bildet er komplisert, hovedsakelig fordi den kristne majoriteten - anført politisk av den maronittiske sekten - var splittet i synet på hvorvidt denne utvidelsen ville gagne beboerne politisk i det lange løp. Majoriteten av innbyggerne i de tilføyde områdene var nemlig av muslimsk bakgrunn, og det ble på kristen side uttrykt bekymring for Libanons videre identitet som en kristen stat. De kristnes andel av Greater Lebanon ble redusert fra rundt 80 prosent til 60 prosent av befolkningen..$^{20} \mathrm{I}$ denne interne striden mellom skeptikere og tilhengere av den territoriale utvidelsen 
"vant" de nasjonalistisk-orienterte tilhengerne av en territorielt sett romsligere stat, der visjonen var å etablere et hjemland for kristne minoriteter under lederskap av Libanons maronitter. Disse hadde sterke historiske bånd til mandatmakten Frankrike. På muslimsk side uttrykte kystbeboerne i sør og innbyggerne i de nordlige og østlige områdene som tidligere lå under Syria, misnøye med og skepsis til å bli løsrevet fra Syria. Denne løsrivelsen underminerte muslimske arabisk-nasjonalistiske aspirasjoner om et Stor-Syria som arnested for en framtidig storarabisk nasjon. ${ }^{21}$

Den territoriale utvidelsen danner et historisk bakteppe for en vedvarende intern uenighet omkring staten Libanons identitet helt siden opprettelsen i I920. Hvilke

\section{Libanon og Syria har siden landenes uavhengighet på 1940-tallet voert enige om å administrere området som libanesisk territorium.}

politiske målsetninger skal myndighetene målbære? En statsidé basert på at landet er arabisk, der hovedforankring og aspirasjoner reflekterer arabisk nasjonalistiske (etter hvert islamsk nasjonalistiske) interesser med en tydelig arabisk lojalitet i forhold til Palestina-Israel konflikten? Eller skal statsidéen reflektere en multikulturell stat, der politiske aspirasjoner strekker seg mot en vestlig interessesfære med Frankrike og (etter hvert) UsA som ideologiske og politiske partnere? Grovt sett reflekterer disse to ideologiene også ulike former for økonomisk politikk. Mens den arabisk-islamistiske tilnærmingen i sterkere grad betoner oppbygging av en stat med større ansvar for befolkningens sosiale sikkerhet, holder den mer vestligorienterte fast ved svak statlig styring. Den siste av disse gir privat eierskap bredt spillerom og innebærer en fortsettelse av en overveiende markedsbasert økonomisk politikk. ${ }^{22}$

Slike uenigheter er ikke unike for Libanon. De gjelder i ulik grad og form mange statsdannelser der innbyggerne tilhører forskjellige språklige, religiøse og etniske grupper, og der ulike økonomiske interesser kan avspeiles i nasjonalpolitikken. Ser man disse ulike politiske aspirasjonene ut fra en klassisk verdiskala med høyre-sentrum-venstre akser, vil man kunne plassere ulike politiske orienteringer og konfliktlinjer langs etter denne aksen. Det spesielle i Libanons tilfelle er at uenigheter omkring statens identitet ble søkt dempet og holdt i sjakk ved å introdusere idéen om fordeling av makt basert på den relative størrelsen av de I7 religiøse gruppene, slik disse ble avspeilt i resultatene av folketellingen i I932. Denne idéen om maktfordeling ble innbakt $i$ den uformelle og uskrevne National Pact av I943, forhandlet fram av landets daværende politiske elite, som også utgjorde landets økonomiske elite. Ettersom folketellingen viste at de kristne var i majoritet, skulle utøvende makt samles i hendene på en maronittisk kristen president, statsministeren skulle være sunnimuslim og parlamentspresidenten skulle ha shi'amuslimsk bakgrunn.

Prinsippet om maktfordeling basert på numerisk styrke kom, ikke uventet, til å virke som en politisk hemsko. I stedet for å tilpasse kartet til terrenget forsøkte libane- 




Libanesiske tropper kjører forbi et portrett av Hizballahs leder Hassan Nasrallah idet de ankommer landsbyen Shab'a den I8. august $\mathrm{i}$ år.

siske myndigheter allerede på I930-tallet å tilpasse terrenget til kartet. ${ }^{23}$ Sagt med andre ord: I mangel på militær evne til å utøve suverenitet overfor periferien, benyttet myndighetene en annen type makt, nemlig statens suverene mulighet til å forhindre vekst $i$ antallet borgere med muslimsk bakgrunn ved å stramme inn tildeling av statsborgerskap. De statsløses krav om å få regulert egen og etterkommeres nasjonalitet ble stanset i ig67. Da forlangte en ny lov at staten skulle være representert som motpart i behandling av alle klagesaker som gjaldt krav om statsborgerskap.

Et innblikk i de politisk betente sidene ved statens utvidelse anno I920, illustrerer sider ved de libanesiske myndigheters manglende interesse for, og etter hvert direkte uvilje til, formell demarkasjon av landets grenser. Det kan derfor være fruktbart å ta høyde for de interne statsborgerlige dimensjonene ved statsbygging $i$ grenseområdene, for å belyse den libanesiske statens labre interesse for å etablere suverenitet over grensetraktene. De geopolitiske dimensjonene kan, med andre ord, suppleres ved innblikk i de statsborgerlige dimensjonene ved statsbyggingsprosessen.

\section{Avslutningsvis}

Motivet for Hizballahs aksjon i Shab'aområdet kan ses på som et påskudd for en fortsettelse av den væpnede kampen mot Israel. Men like fullt illustrerer tvisten om Shab'a-gårdene hvordan uregulerte grensedragninger grunnlagt under mandattiden på I920-tallet skaper konflikter som inntar dagens internasjonale politiske dagsorden.

Den libanesiske regjeringen har flyttet grensespørsmål høyere opp på dagsordenen. Etter denne analysen er dette bare ett av mange ledd i en intern politisk omprioritering av periferiens - den historisk sett 
underprivilegerte befolkningen bosatt i Sør-Libanon og i grensetraktene - krav og målsettinger. Tvisten over Shab'a-gårdene er, slik sett, en indikasjon på Hizballahs styrke til å fronte saker nasjonalt og internasjonalt - selv saker som knapt nok er blitt tatt hensyn til av sentralmyndighetene i Beirut siden uavhengigheten.

Libanons suverenitetskrav over Shab'agårdene vil med stor sannsynlighet forbli et uinnfridd mål så lenge Israel okkuperer Golanhøydene. Dermed er disputten over Shab'a noe som tilhører fredsordninger i et noe lengre perspektiv.

Et forhold som på kort sikt, med stor grad av sannsynlighet vil volde større konflikt er SR I7OIs krav om avvæpning av Hizballah. Hizballah er shi'a-befolkningens ubestridte militære, økonomiske og ideologiske representant, og har sin sterkeste base i Sør-Libanon. Den politiske mobiliseringen libanesere med shi'a-bakgrunn har opplevd de siste to tiår, er blitt bygget på den solide legitimiteten Hizballah har ervervet seg som "frigjøringshær" og "velferdsorgan". Dette utgjør to grunnblokker for robust intern politisk autoritet. Internasjonale krav om demilitarisering av en organisasjon som strutter av selvtillit, uten politisk kompensasjon i en eller annen form, er et lite troverdig utfall av intern libanesisk politikk.

Sett $i$ et historisk statsbyggingsperspektiv, vil en innlemmelse av Hizballahs paramilitære styrker i den ordinære libanesiske nasjonale hæren være en ikke usannsynlig, og i alle fall fruktbar, vei å gå. Hizballahs militære strateger kan, i samarbeid med landets forsvarsdepartement, skue over grensen i sør mot Israel og høste lærdom av hvordan Israels hær er blitt formet. Der vil de finne brukbare løsnings- forslag for ulike måter denne fusjonen kan foregå på. I for- og etterkant av staten Israels opprettelse i i948 ble nemlig dagens israelske hær dannet ved en sammenslåing av ulike sionistiske geriljastyrker og paramilitære enheter. Slike sammenslutninger i det militære forsvarsvesen er også en del av en statsbyggingsprosess.

$$
\cdot f \cdot
$$

I I SR I70I kalles disse gårdene for “Shebaa Farms”. Jeg benytter den arabiske benevnelsen på området.

2 Security Council SC/8808: Security Council calls for the end of hostilities between Hizbollah, Israel, unanimously adopting Resolution I70I (2006), II. august 2006. http://www.un.org./News/Press/docs/2006/sc8808. doc.htm, lesedato, 22. august 2006.

3 Forsker ved Institutt for menneskerettigheter, Cecilie Hellestveit, tar med andre ord feil når hun i et intervju hevder at "[s]tedet hvor de israelske soldatene ble kidnappet den I2. juli er uomtvistelig israelsk område. - Her er det ingen tvil: dette er et brudd på folkeretten og utløser Israels rett til å forsvare seg." (Dagens Næringsliv, 4 . august 2006). Detaljert kart over området der Hizballah opererte finnes i Newsweek 24. juli 2006, s. 2I.

4 Mallat, Chibli: "The Syrian-Israeli boundaries in international law: The significance of the Armistice Demarcation Line of I949", foredrag holdt ved Saint Joseph universitetet i Beirut, I3. juli 2000, www.mallat.com/articles/ fullversion.htm, lesedato: 24 . august 2006.

5 Kaufman, Asher: "Understanding the Sheeba Farms dispute" i Palestine-Israel Journal, vol. II, no. I, 2004.

6 Aftenposten, 23. juli og I4. juli 2006.

7 På hvilket tidspunkt oppstår nasjonsbygging (der landets innbyggere og institusjoner danner en eller annen form for nasjonalt fellesskap) i tillegg til statsbygging, eller hvorvidt disse to prosessene i det hele tatt kan betraktes som atskilte prosesser når det gjelder ikke-europeiske statsdannelser, har fortsatt forskningsmessig akademisk interesse. Jeg lar dette ligge her, men poengterer at skatteinnkreving og verving til en nasjonal hær utgjør to grunnleggende byggesteiner innen statsbygging.

8 Rokkan, Stein: «Stat, nasjon, klasse: Essays i politisk sosiologi». Universitetsforlaget, Oslo I987, s. 216-238. Østerud, Øyvind: «Statsvitenskap: Innføring i politisk analyse». Universitetsforlaget, Oslo 2002, s. 40.

9 Ved Libanons sørlige grense mot nåværende Israel ligger syv landsbyer (på folkemunne kalt al-qura $a l$-sab') som Libanon gjør krav på. De libanesiske juristene Hasan Alawiyya og Joseph Karam påpeker at det i virkeligheten dreier seg om 2I landsbyer som før Paulet-Newcombegrensedragningen i I923 var libanesisk territorium, men som i dag ligger i Israel. Se Alawiyya, Hasan: «Al-jinsiyya allubnaniyya wa turuq isti'dadatiha li-sukkan al-qural 
muqtati'a min lubnan khilalal intidabil faransiyy» [Libane-sisk statsborgerskap og måter å skaffe det på for beboerne som ble utskilt fra Libanon under Det franske mandatet], utgitt privat, I984, og Karam, Joseph: «Aljinsiyya allubnaniyya baynal qanun wal-waqi'» [Libanesisk statsborgerskap mellom lov og virkelighet], Matba'it Joseph al-Hajj, Beirut I993.

IO I en rapport fra Sikkerhetsrådet datert 22. mai 2000 (S/2000/460) påpeker generalsekretæren: "Concerning that portion of Lebanon's border that it shares with the Syrian Arab Republic relevant to the Israeli withdrawal, there seems to be no official record of a formal international boundary agreement between Lebanon and the Syrian Arab Republic that could easily establish the line for the purpose of confirming the withdrawal. On 4 May 2000, the Government of Lebanon informed my Special Envoy that certain farmlands in the Shab'a area located outside the area of operations of UNIFIL as defined since I978 would be claimed by Lebanon in the context of the requirement under resolution 425 (I978) that Israel withdraw from Lebanon.". Report of the Secretary-General on the implementation of Security Council resolutions 425 (I978) and 426 (I978), http://domino.un.org/unispal. NSF/5ba47a5c6cef54Ib802563e000493b8c/97bad2289 I46f58a852568e9006d99bd!OpenDocument, lesedato, 3 . september 2006 .

II Security Council SC/6878: Security Council endorses Secretary-General's conclusion on Israeli withdrawal from Lebanon as of I6 June, http://www.un.org/News/Press/ docs/2000/20000618.sc6878.doc.html, lesedato, I. september 2000 .

I2 Se den franske teksten av avtalen og en arabisk oversettelse i Karam, Joseph I993, op. cit.

I3 Kaufman, Asher 2000, op.cit.

I4 Ifølge FN har Libanon rundt 350 o00 FN-registrerte palestinske flyktninger. Tallet bofaste palestinske flyktninger i landet antas å være langt mindre enn dette, men offisielle tall finnes ikke. Se Gilen, Signe et al.: "Finding Ways: Palestinian Coping Strategies in Changing Environment". Fafo report I77. Falch Hurtigtrykk, Oslo I994.

I5 Den nasjonale hæren har riktignok vært til stede i sør, men har stort sett fungert som politivesen: intern orden ble forsøkt holdt, men hæren maktet aldri å ta kontroll over PLos geriljavirksomhet, og langt mindre forsvare innbyggerne mot israelske luftangrep. Under borgerkrigen (I975-1989) ble hæren splittet opp, og i I979 oppsto South Lebanon Army (sLA) under ledelse av tidligere major Saad Haddad som en nasjonalistisk orientert militshær med støtte fra Israel.

I6 Nida'il-watan, I. september I993, Ad-diyar assiyasi, I. november I993. Se også Alawiyya I984 op. cit. og Karam I993 op. cit.

I7 Av ulike årsaker ble ikke disse innbyggere registrert da den siste folketellingen i landet ble gjennomført i 1932. Mer om I932 folketellingen og statsborgerskapsdekretet av 1994 i Maktabi, Rania: “The I932 Census Revisited: Who are the Lebanese?" i British Journal of Middle Eastern Studies, vol. 26, no. 2, I999.

I8 Al-jazeera.net, 25. april 2005, lesedato: I. september 2006.
I9 Zamir, Meir: «The Formation of Modern Lebanon». Croom Helm, London/Sydney/Dover 1985, s. 98-99.

20 Shehadi, Nadim \& Mills, Dana Haffar, Lebanon: «A History of Conflict and Consensus». London: The Centre for Lebanese Studies in association with I.B. Tauris, I988. Se artikkelen til Kiwan, Fadia: "La perception du GrandLiban ches les maronites dans la période du mandate" og Solh, Raghid: "The attitude of the Arab nationalists towards Greater Lebanon during the I930s".

2I Richards, Alan og Waterbury, John: «The Political Economy of the Middle East: State, Class and Economic Development». Westview Press, Oxford I990, s. 37, 433. Harik, Judith Palmer: «Hizbollah: The Changing Face of Terrorism». Tauris, London 2004.

22 Ved en ny lesning av resultatene av folketellingen i I932 viser det seg at den politiske uenigheten omkring landets identitet ble avspeilet i måten folketellingen ble foretatt på. Den antatte kristne majoriteten var ikke substansiell, og denne majoriteten ble politisk skapt ved at rundt $25 \%$ av de som ble registret som libanesiske var emigranter, hvorav $85 \%$ av disse var av kristen bakgrunn. De aller fleste emigrantene (rundt $80 \%$ ) hadde forlatt landet før I924 og var (naturlig nok) ikke tilstede i landet da folketellingen ble foretatt. Men de kristne nasjonalistene krevde å presentere en numerisk virkelighet i tråd med deres visjon om et kristent Libanon og fikk aksept for å føye emigrantene in absentia til folkeregisteret ved en lov som ble utstedt en måned etter at folketellingen ble varslet. Se Maktabi I999, op. cit. 